\title{
Synthesis and In Vitro Evaluation of $N$-(Bromobut-3-en-2-yl)-7- methoxy-1,2,3,4-tetrahydroacridin-9-amine as a Cholinesterase Inhibitor with Regard to Alzheimer's Disease Treatment
}

Jan Korabecny ${ }^{1}$, Kamil Musilek ${ }^{2, *}$, Ondrej Holas ${ }^{1}$, Eugenie Nepovimova ${ }^{1}$, Daniel Jun ${ }^{3}$, Filip Zemek $^{2}$, Veronika Opletalova ${ }^{1}$, Jiri Patocka ${ }^{4}$, Vlastimil Dohnal ${ }^{5}$, Florian Nachon ${ }^{6}$, Jana Hroudova ${ }^{7}$, Zdenek Fisar ${ }^{7}$ and Kamil Kuca ${ }^{3}$

1 Department of Pharmaceutical Chemistry and Drug Control, Faculty of Pharmacy in Hradec Kralove, Charles University in Prague, Heyrovskeho 1203, 50005 Hradec Kralove, Czech Republic; E-Mail: korabecny.jan@gmail.com (J.K.)

2 Department of Toxicology, Faculty of Military Health Sciences, Trebesska 1575, 50001 Hradec Kralove, Czech Republic

3 Center of Advanced Studies, Faculty of Military Health Sciences, Trebesska 1575, 50001 Hradec Kralove, Czech Republic; E-Mail: kucakam@pmfhk.cz (K.K.)

4 Department of Radiology and Toxicology, Faculty of Health and Social Studies, University of South Bohemia, Ceske Budejovice, Czech Republic; E-Mail: prof.patocka@gmail.com (J.P.)

5 Department of Chemistry, Faculty of Sciences, J.E. Purkinje University, Usti nad Labem, Czech Republic

6 Department of Toxicology, Research Center of Military Health Service (CRSSA), 38702 La Tronche Cedex, France; E-Mail: florian@nachon.net (F.N.)

7 Department of Psychiatry, First faculty of Medicine, Charles University in Prague and General University Hospital in Prague, Prague, Czech Republic

* Author to whom correspondence should be addressed; E-Mail: musilek@pmfhk.cz; Tel.: +420-973-251-523; Fax: +420-495-518-094.

Received: 4 November 2010; in revised form: 30 November 2010 / Accepted: 1 December 2010 / Published: 2 December 2010

Abstract: A new tacrine based cholinesterase inhibitor, $N$-(bromobut-3-en-2-yl)-7methoxy-1,2,3,4-tetrahydroacridin-9-amine (1), was designed and synthesized to interact with specific regions of human acetylcholinesterase and human butyrylcholinesterase. Its inhibitory ability towards cholinesterases was determined and compared to tacrine (THA) 
and 9-amino-7-methoxy-1,2,3,4-tetrahydroacridine (7-MEOTA). The assessment of $\mathrm{IC}_{50}$ values revealed 1 as a weak inhibitor of both tested enzymes.

Keywords: tacrine; acetylcholinesterase; butyrylcholinesterase; 7-MEOTA; inhibition; Alzheimer disease

\section{Introduction}

Alzheimer's disease $(\mathrm{AD})$ is an age-related progressive neurodegenerative disorder that represents an intensive medical need [1]. It is the most common form of dementia, affecting about $5 \%$ of adults over 65 years. Overall, AD is the fifth leading cause of death for US citizens aged 65 and older. The most common symptom is known as progressive difficulties in remembering new information. No treatment is currently available to slow or stop the deterioration of the brain cells in $\mathrm{AD}[1,2]$.

The destruction of cholinergic neurons in the basal forebrain and reduction of choline acetyltransferase (EC 2.3.1.6; ChAT) and acetylcholinesterase (EC 3.1.1.7; AChE) activity in brain tissues in AD patients were first reported in 1976 and 1977 [3,4]. Thus, recent pharmacological research suggests that dysfunctions of specific cholinergic mechanisms may be partially responsible for the decline in memory observed in older age. AD treatment has focused on reducing cognitive decline with cholinesterase inhibitors (ChIs), the treatment of first choice currently available for this purpose.

Tacrine (9-amino-1,2,3,4-tetrahydroacridine; THA; Figure 1) was an effective drug in the treatment of AD [5]. It was approved for clinical use by the U.S. FDA in 1993. However, it exhibited hepatotoxicity via elevation of serum alanine aminotransferase levels and thus showed limited clinical application and it was withdrawn from the pharmaceutical market shortly after its approval. In contrast, 7-MEOTA (9-amino-7-methoxy-1,2,3,4-tetrahydroacridine; Figure 1) was found to be a potent, centrally active $\mathrm{ChI}$ free of the serious side effects related to tacrine [6-9]. In single administration studies, 7-MEOTA was well-tolerated and thus further research efforts are currently aimed at improving its pharmacological profile [10]. The synthesis and biological evaluation of some 7-MEOTA derivatives as novel anti-AD agents was already reported [11,12].

In this study the synthesis, biological evaluation and molecular docking of the potential anti-AD agent $N$-(bromobut-3-en-2-yl)-7-methoxy-1,2,3,4-tetrahydroacridin-9-amine (1, Figure 1).

Figure 1. Structures of THA, 7-MEOTA and analogue 1.<smiles>Nc1c2c(nc3ccccc13)CCCC2</smiles>

THA<smiles>COc1ccc2nc3c(c(N)c2c1)CCCC3</smiles>

7-MEOTA<smiles>C=CC(CBr)Nc1c2c(nc3ccc(OC)cc13)CCCC2</smiles> 


\section{Results and Discussion}

Compound 1 has been synthesized by a nucleophilic substitution reaction. Firstly, 9-amino-7methoxy-1,2,3,4-tetrahydroacridine (7-MEOTA) was deprotonated using potassium hydroxide in DMSO at room temperature and the aromatic amine of 7-MEOTA was thus prepared. The planned reaction presumed nucleophilic substitution of 7-MEOTA with (E)-1,4-dibromo-but-2-ene and formation of 7-MEOTA dimer - 9,9`-((E)-but-2-ene-1,4-diyldiimino)-di-(7-methoxy-1,2,3,4-tetrahydroacridine) - but this dimer was not obtained and a different product was produced by a different mechanism that involved in the first step a $\beta$-elimination reaction (Scheme 1) with a bimolecular transition state. The $\beta$-proton of (E)-1,4-dibromo-but-2-ene was removed via leaving group assistance and a carbocation was produced. This activated carbocation was coupled with 7-MEOTA base via nucleophilic substitution and $N$-(bromobut-3-en-2-yl)-7-methoxy-1,2,3,4-tetrahydroacridin-9-amine (1) was thus formed (Scheme 1, compound 1) [13], although in very low yield (2\%). This mechanism has not been previously described.

Scheme 1. Proposed mechanism of 7-MEOTA reaction with (E)-1,4-dibromo-but-2-ene.<smiles>C=CC(CBr)Nc1c2c(nc3ccc(OC)cc13)CCCC2</smiles>

In vitro assessment showed that $\mathbf{1}$ was weak a ChI compared to THA and 7-MEOTA for both tested enzymes - human recombinant AChE (hAChE) and human plasmatic BChE (hBChE). Additionally, 1 was found to be a two orders of magnitude worse inhibitor of hAChE when compared with THA and a three orders of magnitude weaker inhibitor of $\mathrm{hBChE}$ in comparison with THA. Similar results were observed comparing 1 to its parent compound (7-MEOTA), where 7-MEOTA showed better inhibitory ability towards hAChE and hBChE (Figures 2-3). The selectivity index (SI) for hAChE was calculated (Table 1). Comparing SI, 1 was more than fifteen fold more selective towards hAChE than THA, but it didn’t exceed 7-MEOTAwhich was a slightly more selective inhibitor of hAChE.

Table 1. $\mathrm{IC}_{50}$ values of tested compound and standards.

\begin{tabular}{|c|c|c|c|}
\hline Compound & $\begin{array}{c}\text { hAChE } I_{50} \pm \text { SD } \\
(\mu M)\end{array}$ & $\begin{array}{c}\text { hBChE } I_{50} \pm \text { SD } \\
(\mu \mathrm{M})\end{array}$ & $\begin{array}{c}\text { SI } \\
\text { hBChE/hAChE }\end{array}$ \\
\hline THA & $0.5 \pm 0.1$ & $0.02 \pm 0.003$ & 0.05 \\
\hline 7-МЕОТА & $15.0 \pm 2.4$ & $21.0 \pm 3.4$ & 1.4 \\
\hline 1 & $89.1 \pm 17.3$ & $78.8 \pm 12.8$ & 0.88 \\
\hline
\end{tabular}


Figure 2. Enzyme activity plot of 1, THA and 7-MEOTA for hAChE.

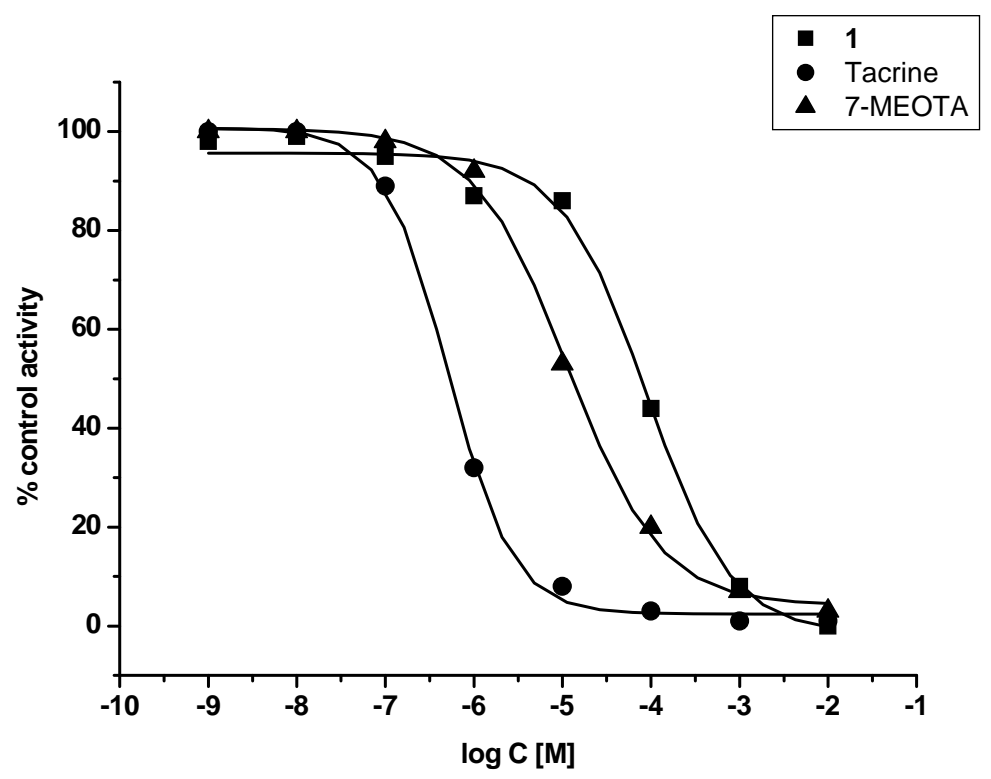

Figure 3. Enzyme activity plot of 1, THA and 7-MEOTA for hBChE.

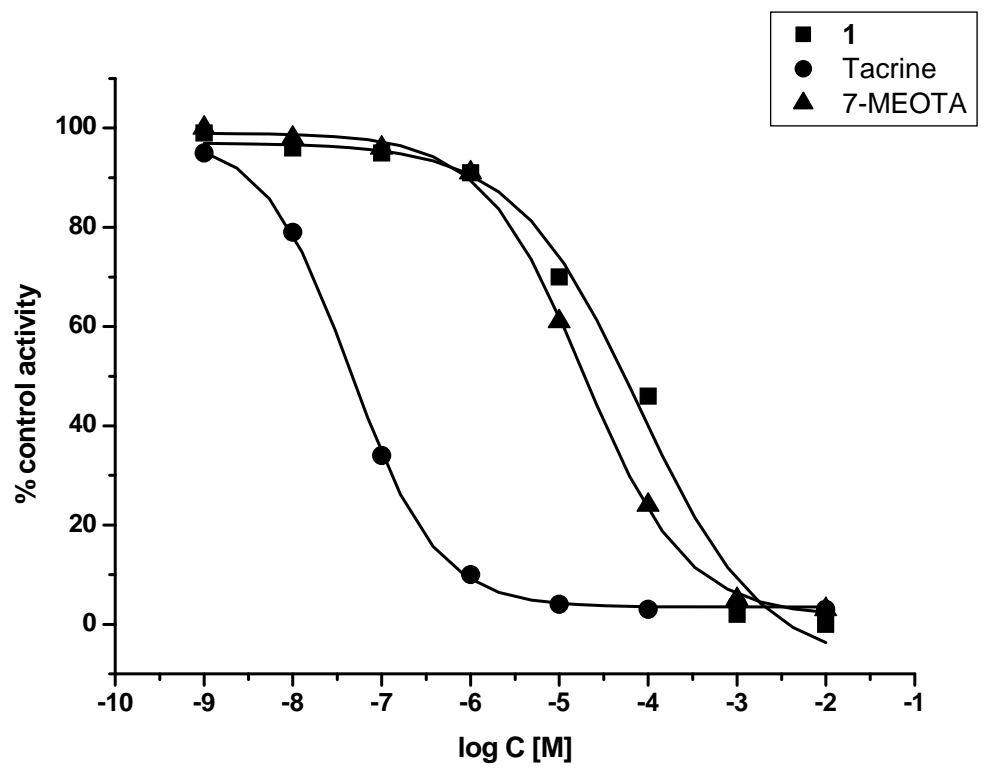

Molecular docking was performed in order to rationalize the in vitro findings. The tAChE crystal structure with THA (1acj) was chosen as a relevant enzyme source due to the similar molecular structures of THA, 7-MEOTA and compound 1 [14]. The THA molecule (in blue) remained the same as in the acquired crystal structure and is visualized together with the top-scored docking poses of 7-MEOTA molecule (in yellow; Figure 4). Both compounds displayed binding to the cation- $\pi$ site of tAChE with very similar spatial orientations. The crystal structure of THA is stacked between $\operatorname{Trp} 84$

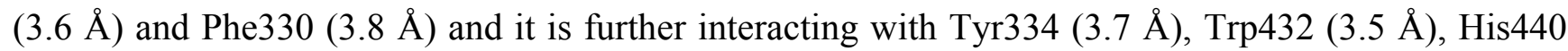
$(4.3 \AA)$ and Tyr $442(3.8 \AA)$. Additionally, the 9-amino moiety is attached by hydrogen bonds to two water molecules (2.1 and $2.2 \AA)$. 
Similarly, the top-scored docking pose of 7-MEOTA $(-8.24 \mathrm{kcal} / \mathrm{mol})$ showed apparent $\pi-\pi$ interactions with Trp84 (3.6 $\AA$ ) and Phe330 (3.8 $\AA$ ). However, it resulted 180 degrees rotated from THA with same position of the 9-amino moiety, whereas the hydrogen bonds with two water molecules (both $2.2 \AA$ ) remained similar and its 7-methoxy moiety was attached by hydrogen bond to Gly118 (3.3 $\AA$ ). This rotation of 7-MEOTA may explain its lower inhibitory ability towards AChE $(15 \mu \mathrm{M})$ compared to THA $(0.5 \mu \mathrm{M})$, where the aromatic ring with 7-methoxy moiety remained a bit distant from other important AChE aromatic residues (Tyr334, Trp432, Tyr442).

The top-scored docking pose of compound $1(-5.60 \mathrm{kcal} / \mathrm{mol})$ displayed a different type of binding, interacting with tAChE residues of the peripheral active site (PAS). Importantly, it was attached to $\operatorname{Trp} 279$ (3.6 $\AA$ ) and Phe290 (3.7 $\AA$ ) by $\pi-\pi$ interactions. Additionally, the aromatic nitrogen and secondary amino group showed interactions with two water molecules (2.0 and $2.3 \AA$ ). Its binding at the rim of the AChE gorge may well justify its low in vitro inhibitory ability $(89 \mu \mathrm{M})$, where it was not able to close the AChE gorge and prevent to decomposition of the substrate (acetylthiocholine).

Figure 4. Molecular docking results for THA, 7-MEOTA and compound 1.

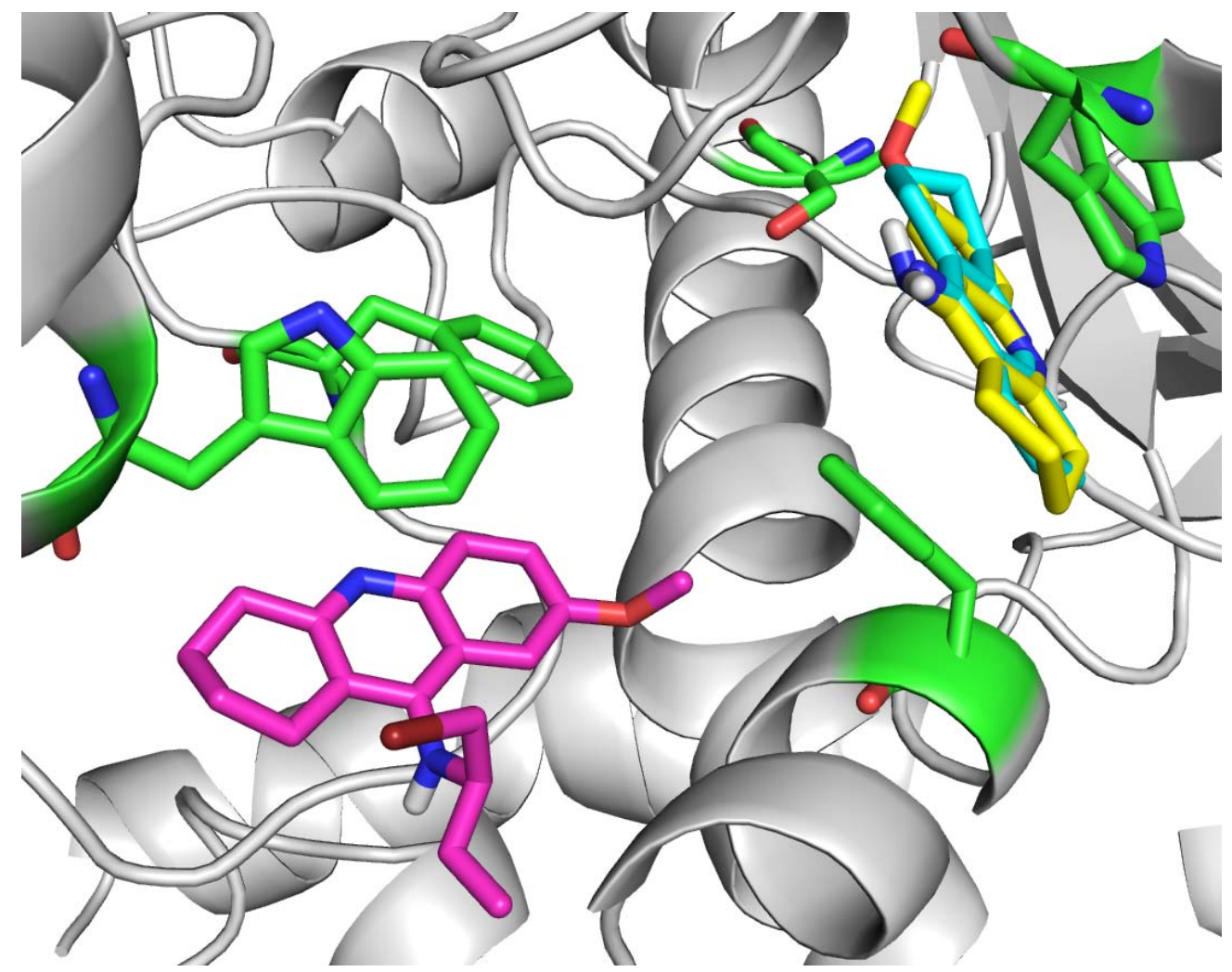

\section{Experimental}

\subsection{Chemistry}

7-MEOTA was prepared at our department according to the method described earlier [15]. All reagents were obtained from commercial sources in reagent grade quality. All experiments were carried out under nitrogen atmosphere. Thin layer chromatography (TLC) was performed on aluminium sheets precoated with silica gel $60 \mathrm{~F}_{254}$ (Merck). Column chromatography was performed at normal pressure on silica gel 100 (particle size 0.063-0.200 mm, 70-230 mesh ASTM, Fluka). 
Elemental analyses were obtained on a Perkin-Elmer CHN Analyser 2400 Serie II apparatus. Mass spectra were recorded using a combination of high performance liquid chromatography and mass spectrometry. The HP1100 HPLC system was obtained from Agilent Technologies (Waldbronn, Germany). It consisted of a G1322A vacuum degasser, G1311A quaternary pump, G1313A autosampler and a MSD1456 VL quadrupole mass spectrometer equipped with an electrospray ionization source. Nitrogen for the mass spectrometer was supplied by a Whatman 75-720 nitrogen generator. Data were collected in positive ion mode with an ESI probe voltage of 4,000 V. The pressure of nebulizer gas was set up to $35 \mathrm{psig}$. Drying gas temperature was operated at $335{ }^{\circ} \mathrm{C}$ and flow at $13 \mathrm{~L} / \mathrm{min}$. ${ }^{1} \mathrm{H}-\mathrm{NMR}$ and ${ }^{13} \mathrm{C}$-NMR spectra were recorded with a Varian Mercury VX BB 300 spectrometer operating at 300 and $75 \mathrm{MHz}$, respectively, using tetramethylsilane (TMS) as reference. Chemical shifts are reported in parts per milion $(\mathrm{ppm}, \delta$ ) relative to TMS. Melting points were measured on a micro heating stage PHMK 05 (VEB Kombinant Nagema, Radebeul, Germany) and are uncorrected.

\subsection{In vitro evaluation}

A Sunrise multichannel spectrophotometer (Tecan, Salzburg, Austria) was used for all cholinesterase activity measurements. A previously optimized Ellman procedure was slightly modified in order to estimate anticholinergic properties [16]. 96-well photometric microplates made from polystyrene (Nunc, Rockilde, Denmark) were used for measuring purposes. Human recombinant AChE or human plasmatic BChE (Aldrich; commercially purified by affinity chromatography) were suspended into phosphate buffer ( $\mathrm{pH} 7.4)$ up to final activity $0.002 \mathrm{U} / \mu \mathrm{L}$. Cholinesterase $(5 \mu \mathrm{L})$, freshly mixed solution of $0.4 \mathrm{mg} / \mathrm{mL} \quad 5,5^{\prime}$-dithio-bis(2-nitrobenzoic) acid $(40 \mu \mathrm{L}), 1 \mathrm{mM}$ acetylthiocholine chloride in phosphate buffer $(20 \mu \mathrm{L})$ and appropriate concentration of inhibitor (1 $\mathrm{mM}-0.1 \mathrm{nM} ; 5 \mu \mathrm{L}$ ) were injected per well. Absorbance was measured at $412 \mathrm{~nm}$ after 5 minutes incubation using automatic shaking of the microplate. The obtained data were used to compute percentage of inhibition (I; Equation (1)):

$$
I=1-\frac{\Delta A_{i}}{\Delta A_{0}} \quad[\%]
$$

where $\Delta \mathrm{A}_{\mathrm{i}}$ indicates absorbance change provided by cholinesterase exposed to AChE inhibitors and $\Delta \mathrm{A}_{0}$ indicates absorbance change caused by intact cholinesterase (phosphate buffer was applied instead of AChE inhibitor). $\mathrm{IC}_{50}$ values were calculated using Origin 6.1 (Northampton, MA, USA). Percentage of inhibition for the given anticholinergic compound was overlaid by proper curve chosen according to optimal correlation coefficient. $\mathrm{IC}_{50}$ as well as upper limit of inhibition (maximal inhibition provided by given compound) was computed.

\subsection{Synthesis of N-(bromobut-3-en-2-yl)-7-methoxy-1,2,3,4-tetrahydroacridin-9-amine (1)}

Powdered potassium hydroxide $(636 \mathrm{mg}, 11.3 \mathrm{mmol})$ was added to a solution of 7-MEOTA $(1,000 \mathrm{mg}, 3.8 \mathrm{mmol})$ and DMSO $(20 \mathrm{~mL})$. The mixture was vigorously stirred at room temperature for 2 hours. Then $(E)$-1,4-dibromo-but-2-ene $(808 \mathrm{mg} ; 3.8 \mathrm{mmol})$ was added and the stirring was continued for further 48 hours at room temperature. The end of reaction was determined on a 
triethylamine-saturated TLC plate, mobile phase hexane/ethyl-acetate $(1: 1)$. Water $(100 \mathrm{~mL})$ was poured into the reaction mixture and the water phase was extracted with ethyl acetate $(4 \times 60 \mathrm{~mL})$. The combined organic extracts were dried over anhydrous sodium sulfate, filtered and evaporated under reduced pressure to give an oily residue that was purified by column chromatography on triethylaminesaturated silica gel. A 1:1 hexane/ethyl-acetate mobile phase was used for purification. The pure product was isolated as brown crystals [11,12,17]. Yield: $20 \mathrm{mg}(2 \%)$; m.p. 100.8-103.9 ${ }^{\circ} \mathrm{C} ;{ }^{1} \mathrm{H}-\mathrm{NMR}$ (chloroform- $\mathrm{d}_{3}$ ): 7.81 (d, $J=9.08 \mathrm{~Hz}, 1 \mathrm{H},-\mathrm{O}-\mathrm{C}-\mathrm{CH}-\underline{\mathrm{CH}}-$ ), 7.34 (d, $J=2.64 \mathrm{~Hz}, 1 \mathrm{H},-\mathrm{O}-\mathrm{C}-\mathrm{CH}-\mathrm{C}-$ ), $7.23\left(\mathrm{dd}, J_{1}=2.64 \mathrm{~Hz}, J_{2}=9.08 \mathrm{~Hz},-\mathrm{O}-\mathrm{C}-\underline{\mathrm{CH}}-\mathrm{CH}-\right), 5.97-5.82\left(\mathrm{~m}, 1 \mathrm{H}, \mathrm{CH}_{2}=\underline{\mathrm{CH}}-\right)$, 5.62 (dd, $\left.J_{1}=1.17 \mathrm{~Hz}, J_{2}=17.29 \mathrm{~Hz}, 2 \mathrm{H},(Z)-\underline{\mathrm{CH}}_{2}=\mathrm{CH}-\right), 5.42\left(\mathrm{dd}, J_{1}=1.17 \mathrm{~Hz}, J_{2}=10.55 \mathrm{~Hz}, 2 \mathrm{H},(E)-\right.$ $\left.\underline{\mathrm{CH}}_{2}=\mathrm{CH}-\right), 3.88\left(\mathrm{~s}, 3 \mathrm{H}, \mathrm{CH}_{3}-\mathrm{O}-\right), 3.04\left(\mathrm{t}, J=5.57 \mathrm{~Hz}, 2 \mathrm{H},=\mathrm{N}-\mathrm{C}-\mathrm{CH}_{2}-\right), 2.90$ (t, $J=5.86 \mathrm{~Hz}, 2 \mathrm{H},-\mathrm{N}-\mathrm{C}-$ C- $\left.\mathrm{CH}_{2}-\right), 2.90-2.85\left(\mathrm{~m}, 1 \mathrm{H}, \mathrm{CH}_{2}=\mathrm{CH}-\underline{\mathrm{CH}}-\right), 2.61$ (dd, $\left.J_{1}=0.88 \mathrm{~Hz}, J_{2}=3.52 \mathrm{~Hz}, 2 \mathrm{H}, \mathrm{Br}-\underline{\mathrm{CH}_{2}} \mathrm{CH}^{*}-\right)$, $2.43\left(\mathrm{dd}, J_{1}=0.88 \mathrm{~Hz}, J_{2}=6.45 \mathrm{~Hz}, 2 \mathrm{H}, \mathrm{Br}-\underline{\mathrm{CH}}_{2}-\mathrm{CH}^{*}-\right), 2.06-1.69\left(\mathrm{~m}, 4 \mathrm{H},=\mathrm{C}^{-} \mathrm{CH}_{2}-\mathrm{CH}_{2}-\mathrm{CH}_{2}-\mathrm{CH}_{2}-\mathrm{C}=\right)$; ${ }^{13} \mathrm{C}-\mathrm{NMR}$ (chloroform- $\mathrm{d}_{3}$ ): 156.57, 156.14, 153.11, 143.07, 137.04, 130.29, 121.86, 120.91, 120.50, 118.44, 100.91, 55.59, 43.25, 37.58, 33.40, 26.02, 22.96, 22.83; ESI-MS: m/z $361.0[\mathrm{M}]^{+}$(calculated for: $\left[\mathrm{C}_{18} \mathrm{H}_{22} \mathrm{~N}_{2} \mathrm{O}\right]^{+} 361.3$ ); Elemental analysis: calculated $59.84 \% \mathrm{C}, 5.86 \% \mathrm{H}, 7.75 \% \mathrm{~N}$; found 60.01 $\%$ C, $5.91 \% \mathrm{H}, 7.65 \% \mathrm{~N}$

\subsection{Molecular docking}

Docking calculations were carried out using AutoDockVina 1.1.1. [18]. The structure of Torpedo californica AChE (tAChE) was prepared from the crystal structure (pdb code 1acj) using Autodock Tools 1.5.2. [19-20]. The molecular models of ligands were built in ChemDraw 11.0 and minimized with UCSF Chimera 1.3 (Amber Force field) in charged form [21]. Docking calculations were set to 50 runs. A population of 150 individuals and 2,500,000 function evaluations were used. The structure optimization was performed for 27,000 generations using a genetic algorithm. Maximum root mean square tolerance for conformational cluster analysis was $2.0 \AA$. At the end of calculation, AutoDock Vina performed cluster analysis. The visualisation of enzyme-ligand interactions (Figure 4) was prepared using Pymol 1.1.8. [22].

\section{Conclusion}

In summary, the new cholinesterase inhibitor $N$-(bromobut-3-en-2-yl)-7-methoxy-1,2,3,4tetrahydroacridin-9-amine (1) was synthesized. It was produced by a nucleophilic reaction of 7MEOTA with (E)-1,4-dibromobut-2-ene. This compound was found to be poor inhibitor of cholinesterases in vitro, but it showed 15-fold higher selectivity towards hAChE compared to THA. The molecular docking study found different binding of THA or 7-MEOTA compared to compound 1 and explained its low inhibitory ability in vitro.

\section{Acknowledgements}

Authors kindly appreciated the support of Ministry of Education, Youth and Sport (No. MSM0021620822; SVV-2010-261-001), Czech Grant Agency (No. P303/11/1907) and Ministry of 
Defence of the Czech Republic (No. OVUOFVZ200805). The work was supported by the Czech Neuropsychopharmacological Society.

\section{References}

1. Selkoe, D.J. Alzheimer's disease: Genes, proteins, and therapy. Physiol. Rev. 2001, 81, 741-766.

2. Walsh, D.M.; Selkoe, D.J. Deciphering the molecular basis of memory failure in Alzheimer's disease. Neuron 2004, 44, 181-193.

3. Davies, P.; Maloney, A.J.F. Selective loss of central cholinergic neurons in Alzheimer's disease. Lancet 1976, 2, 1403.

4. Perry, E.K.; Perry, R.H.; Blessed, G.; Tomlinson, B.E. Necropsy evidence of central cholinergic deficits in senile dementia. Lancet 1997, 1, 189.

5. Summers, W.K.; Majowski, L.V.; Marsh, G.M.; Tachiki, K.; Kling, A. Oral tetrahydroacridineamine in long term treatment of senile dementia, Alzheimer type. N. Engl. J. Med. 1986, 315, 1241-1245.

6. Watkins, P.B.; Zimmerman, H.J.; Knapp, M.J.; Gracon, S.I.; Lewis, K.W. Hepatotoxic effects of tacrine administration in patients with Alzheimer-disease. Jama-J. Am. Med. Assoc. 1994, 271, 992-998.

7. Marx, J.L. Alzheimer's drug trial put on hold. Science 1987, 238, 1041-1042.

8. Ames, D.J.; Bhathal, P.S.; Davies, B.M.; Fraser, J.R.E. Hepatotoxicity of tetrahydroacridine. Lancet 1988, 1, 887.

9. Patocka, J.; Jun, D.; Kuca, K. Possible role of hydroxylated metabolites of tacrine in drug toxicity and therapy of Alzheimer's disease. Curr. Drug Met. 2008, 9, 332-335.

10. Filip, V.; Vachek, J.; Albrecht, V.; Dvorak, I.; Dvorakova, J.; Fusek, J.; Havluj, J. Pharmacokinetics and tolerance of 7-methoxytacrine following the single dose administration in healthy-volunteers. Int. J. Clin. Pharm. Ther. Toxicol. 1991, 29, 431-436.

11. Korabecny, J.; Holas, O.; Musilek, K.; Pohanka, M.; Opletalova, V.; Dohnal, V.; Kuca, K. Synthesis and In Vitro Evaluation of New Tacrine Derivates-Bis-Alkylene Linked 7-MEOTA. Lett. Org. Chem. 2010, 7, 327-331.

12. Korabecny, J.; Musilek, K.; Holas, O.; Binder, J.; Zemek, F.; Marek, J.; Pohanka, M.; Opletalova, V.; Dohnal, V.; Kuca, K. Synthesis and in vitro evaluation of $\mathrm{N}$-alkyl-7-methoxytacrine hydrochlorides as potential cholinesterase inhibitors in Alzheimer disease. Bioorg. Med. Chem. Lett. 2010, 20, 6093-6095.

13. McLennan, D.J. A revised transition state spectrum for concerted bimolecular $\beta$-eliminations. Tetrahedron 1975, 31, 2999.

14. Harel, M.; Schalk, I.; Ehret-Sabatier, L.; Bouet, F.; Goeldner, M.; Hirth, C.; Axelsen, P.H.; Silman, I.; Sussman, J.L. Quaternary ligand binding to aromatic residues in the active-site gorge of acetylcholinesterase. Proc. Natl. Acad. Sci. USA 1993, 90, 9031-9035.

15. Patocka, J. Anticholinesterase activity of 9-amino-7-methoxy-1,2,3,4-tetrahydroacridine and some derivatives and analogues. Sbornik Ved. Prac. VLVDU Hradec Kralove 1986, 102, 123-140.

16. Pohanka, M.; Jun, D.; Kuca, K. Improvement of acetylcholinesterase-based assay for organophosphates in way of identification by reactivators. Talanta 2008, 77, 451-454. 
17. Pang, Y.-P.; Hong, F.; Quiram, P.; Jelacic, T.; Brimijon, S. Synthesis of alkylene linked bis-THA and alkylene linked benzyl- THA as highly potent and selective inhibitors and molecular probes of acetylcholinesterase. J. Chem. Soc., Perkin Trans. 1 1997, 171-176.

18. Trott, O.; Olson, A.J. AutoDock Vina: improving the speed and accuracy of docking with a new scoring function, efficient optimization and multithreading. J. Comput. Chem. 2010, 31, 455-461.

19. Potein crystal structures are available online http://www.pdb.org. Accessed on 1st October 2010.

20. Morris, G.M.; Goodsell, D.S.; Halliday, R.S.; Huey, R.; Hart, W.E.; Belew, R.K.; Olson, A.J. Automated docking using a lamarckian genetic algorithm and and empirical binding free energy function. J. Comput. Chem. 1998, 19, 1639-1662.

21. Pettersen, E.F.; Goddard, T.D.; Huang, C.C.; Couch, G.S.; Greenblatt, D.M.; Meng, E.C.; Ferrin, T.E. UCSF Chimera - A visualization system for exploratory research and analysis. J. Comput. Chem. 2004, 25, 1605-1612.

22. DeLano, W.L. The PyMOL Molecular Graphics System (2002). Available online http://www.pymol.org/. Accessed on 1 October 2010.

Sample Availability: Samples of the compounds THA, 7-MEOTA and 1 are available from authors.

(C) 2010 by the authors; licensee MDPI, Basel, Switzerland. This article is an open access article distributed under the terms and conditions of the Creative Commons Attribution license (http://creativecommons.org/licenses/by/3.0/). 